\title{
CONCEPÇÕES DE "TRABALHO DOCENTE": AS CONDIÇÕES CONCRETAS E OS DISCURSOS DAS PRESCRIÇÕES OFICIAIS*
}

\author{
ANA LÚCIA HoRTA NogueIRA*
}

\begin{abstract}
RESUMO: Este texto focaliza o trabalho do professor em suas relações com as prescrições oficiais e as condições de trabalho na instituição escolar. Como os professores descrevem os impactos das condições de trabalho a que estão submetidos? Quais são suas reivindicações? Como as condições e as especificidades do trabalho docente são contempladas nos documentos oficiais? Estas questões são problematizadas a partir da explicitação dos sentidos de "trabalho docente" em circulação em alguns documentos elaborados nas últimas décadas. As análises apontam que as concepções presentes nos documentos estão correlacionadas à disputa de posições ideológicas neste contexto, posições que constituem o (trabalho do) professor.
\end{abstract}

Palavras-chave: Trabalho docente. Condições de trabalho. Política educacional.

\section{“THE WORK OF THE TEACHER" CONCEPTIONS: THE CONCRETE CONDITIONS AND THE OFFICIAL PRESCRIPTIONS DISCOURSES}

ABSTRACT: This article focuses on the on the work of the teacher and its relationship with the official prescriptions and the working conditions at school: How do teachers describe the impacts of the working conditions which they are submitted to? What are their expectations? How are the working conditions and the teaching specificities treated in official documents? Those questions are discussed from the meanings of "the work of the teacher" concept's perspective found in documents developed in the last decades. The analyses indicate that the notions present in these documents are correlated to the debate between the ideological positions taking part in this context, positions that constitute (the work of) the teacher.

Key words: The work of the teacher. Working conditions. Educational policy.

* Este artigo expande a apresentação "The constitution of the teacher work: the concrete conditions and the official prescriptions", feita no Congresso da International Society for Cultural and Activity Research (Iscar), em Roma (2011).

* Pós-doutora em Linguística Aplicada e professora da Faculdade de Filosofia, Ciências e Letras da Universidade de São Paulo (USP), em Ribeirão Preto. E-mail: anahnogueira@ffclrp.usp.br 


\title{
Conceptions du "TRAVAIl ENSEIGNANT": LES CONDitions
} CONCRETES ET LES DISCOURS DES PRESCRIPTIONS OFFICIELLES

\begin{abstract}
RÉSUMÉ: Ce texte se concentre sur le travail du professeur dans ses relations avec les prescriptions officielles et les conditions de travail dans l'institution scolaire. Comment les professeurs décrivent les impacts des conditions de travail auxquelles ils sont soumis? Quelles sont leurs revendications? Comment les conditions et les spécificités du travail enseignant sont traitées dans les documents officiels ? Ces questions sont problématisées à partir de l'explication des sens du "travail enseignant" en circulation dans quelques documents élaborés dans les dernières décennies. Les analyses démontrent que les conceptions présentes dans les documents sont corrélées à la dispute de positions idéologiques dans ce contexte, positions qui constituent le (travail du) professeur.
\end{abstract}

Mots-clés: Travail enseignant. Conditions de travail. Politique éducationnelle.

\section{Introdução}

$\mathrm{E}$

$\mathrm{m}$ estudo realizado com alguns professores da rede pública de ensino em uma cidade do interior do estado de São Paulo (Barros, 2009), foi possível identificar que grande parte das "frustrações e desapontamentos" que o professor encontra na realização das tarefas profissionais cotidianas está enraizada nas condições concretas de trabalho produzidas pela organização institucional, como sobrecarga de trabalho, grande número de alunos em sala de aula, ausência de materiais para as aulas, dificuldade para efetivar as propostas oficiais por falta de apoio institucional, pequeno reconhecimento profissional, além da dificuldade para efetivar as atividades planejadas e do descontentamento com a própria forma de atuação.

Os aspectos indicados pelos professores que participaram deste estudo vão no mesmo sentido das tendências apuradas em ampla consulta realizada pela Confederação Nacional dos Trabalhadores em Educação (CNTE) em escolas das redes públicas, junto a pais, alunos e profissionais da educação, cujos resultados estão sistematizados nos relatórios Retrato da Escola 1, 2 e 3 (CNTE, 1999, 2001, 2003). ${ }^{1}$

Conforme Retrato da Escola 1 (CNTE, 1999), a questão do "número excessivo de alunos/as por sala de aula" é o primeiro dos fatores indicados como os principais problemas da escola e da educação. No tópico da profissionalização, os "salários indignos" ocupam o primeiro lugar, aspecto que se repete no tópico das reivindicações dos trabalhadores em educação, seguido por reivindicações ligadas à formação permanente, à carreira e à melhoria da infraestrutura e condições de trabalho, quando reaparece a questão do "número de alunos adequado por turma, equipamentos e materiais didáticos".

Os relatórios focalizam o trabalho do professor de um modo - atividade situada e contingenciada pelas condições concretas - raramente presente em documentos 
oficiais. A maioria dos documentos, como propostas de programas ou reformas educacionais, passa ao largo ou trata a questão das condições concretas de trabalho de forma marginal. Enraizado no esforço de racionalização do trabalho de forma a ocultar as verdadeiras dimensões da atividade humana de trabalho, o predomínio do olhar sobre o trabalho como atividade de simples "execução" e despojada de suas habilidades, ajustes e circunstâncias, acarreta um "subdimensionamento" de suas especificidades, um "desconhecimento bastante profundo do que ocorre verdadeiramente no trabalho humano" (Schwartz, 1996, p. 115).

Instigados por esta situação e buscando compreender os sentidos de "trabalho docente" em circulação, levantamos documentos elaborados em diferentes instâncias institucionais, com a participação de órgãos governamentais nacionais e internacionais ou de entidades de classe. Considerando a perspectiva da ergonomia francesa e da linguística para análise do trabalho, que propõe a noção de ensino como trabalho (Amigues, 2004; Machado, 2007), a análise de documentos sobre este tema permite indicar diferentes concepções da relação entre trabalho, condições de trabalho e necessidades que emergem no seu exercício cotidiano. Por meio da linguagem sobre o trabalho pode-se explicitar a rede discursiva que se constrói na e sobre determinada atividade - as concepções do trabalho educacional nos diferentes textos. Buscamos, assim, um caminho para romper com o "ocultamento do trabalho efetivo dos professores" e contribuir para o entendimento da especificidade do trabalho docente (Nouroudine, 2002; Bronckart \& Machado, 2004; Machado \& Bronckart, 2005; Bronckart, 2006; Schwartz, 1996).

\section{O trabalho do professor nos documentos oficiais}

Para efeitos deste texto, entre os inúmeros documentos oficiais que tratam do trabalho do professor, analisamos trechos dos seguintes: Recomendação relativa à condição docente (Unesco-OIT, 1966), Educação: um tesouro a descobrir (Relatório Delors: Relatório para a Unesco da Comissão Internacional sobre Educação para o século XXI, 1996), Resolução n. 2/2009 e Parecer n. 9/2009 (Brasil, 2009a, 2009b), Portaria Normativa do Ministro da Educação n. 14/2010 (Brasil, 2010b), Portaria Normativa do Ministro da Educação n. 3/2011 (Brasil, 2011b), Retrato da escola (CNTE, 1999); Diretrizes para a carreira e remuneração (Cadernos de Educação, CNTE, 2009). ${ }^{2}$

Diante do grande conjunto de documentos, não pretendemos uma análise exaustiva, tampouco esgotar todas as questões por eles suscitadas. A opção por trazer documentos produzidos em diferentes instâncias institucionais ao longo dos últimos anos se justifica pela possibilidade de explicitar como diferentes vozes se entretecem e produzem nuanças acerca do trabalho do professor. 


\section{0 discurso das entidades internacionais}

A Recomendação Relativa à Condição Docente, amplo documento elaborado por um comitê internacional da Unesco-OIT, em 1966 (146 cláusulas em 35 páginas), constitui importante marco com relação à discussão sobre o trabalho do professor. Dentre os inúmeros aspectos discutidos, ressaltamos a definição inicial:

a) $\mathrm{O}$ termo "docente" designa todas as pessoas que nas escolas assumem a responsabilidade da educação dos alunos;

b) O termo "condição", empregado em relação ao docente, designa, simultaneamente, posição social reconhecida na sociedade, de acordo com o grau de consideração atribuído a sua função, assim como sua competência, condições de trabalho, remuneração e vantagens materiais garantidas em comparação com outras profissões. (Unesco, 1966, p. 5)

A opção por tratar da "condição docente" já sinaliza uma concepção de docência como situação favorecida por certas condições: "o conceito de condição como limitação de possibilidades objetivas e, portanto, como previsibilidade provável do evento" (Abbagnano, 2007, p. 201). O termo "condição docente" rompe com a descontextualização e naturalização da atividade do professor, inserindo-a no contexto das especificidades e condições materiais de trabalho historicamente constituídas, conforme a cláusula n. 8: "As condições de trabalho docente devem favorecer ao máximo a eficácia do ensino e permitir-lhes dedicação total as suas tarefas profissionais" (Unesco, 1966, p. 6).

Como indicam as principais cláusulas relativas às condições de trabalho, o trabalho do professor é contingenciado por aspectos concretos que conferem qualidade ao ensino: "número de alunos em sala de aula deve ser reduzido em quantidade tal que permita ao professor ocupar-se pessoalmente de cada"; reconhecimento da especificidade da atividade de ensino e garantia aos docentes de "plena dedicação ao exercício de suas funções"; acesso aos recursos didáticos; condições de remuneração adequadas à função e suficientes para qualificação profissional e acesso aos bens culturais (idem, ibid., p. 6 e 23).

O destaque às condições e meios de ensino se aproxima dos argumentos de Amigues (2004, p. 41) acerca da atividade do professor como "atividade instrumentada e direcionada", que "busca seus meios de agir nas técnicas profissionais que se constituíram no decorrer da história da escola e do ofício do professor", por meio das prescrições, dos coletivos de trabalho, das regras do ofício, das ferramentas e instrumentos para o trabalho. Desse modo, o documento se opõe à concepção de ensino como "atividade individual, limitada à sala de aula e às interações com os alunos, atividade que se praticaria sem ferramentas, fora de qualquer tradição profissional" (ibid., p. 45). 
A Recomendação "reconheceu o papel primordial do pessoal docente para o desenvolvimento da educação de qualidade e sua contribuição para a plenitude da personalidade humana e da sociedade. Talvez ela seja o mais completo documento sobre a profissionalização docente" (Cunha, 2009, p. 148). Entretanto, em termos históricos, seu impacto foi bastante reduzido no contexto geral da educação, fato que pode estar relacionado à própria natureza sugestiva do documento. Além disso, quando a Recomendação foi aprovada, "o Brasil já estava sob o regime militar, com fortes implicações na política educacional. Aspirações e propostas que haviam sido pensadas e engendradas antes do golpe militar de 1964 foram abandonadas e substituídas pela dimensão tecnicista da pedagogia desse tempo" (idem, ibid., p.149), contexto no qual se intensificou a desvalorização do trabalho docente na educação básica.

Retomamos agora o Relatório Delors, elaborado sob a responsabilidade da Unesco, em 1996, trinta anos após a elaboração da Recomendação Relativa à Condição Docente. Bastante extenso (288 páginas), o documento abrange vários tópicos, desde a análise de aspectos sociais, políticos e econômicos até a formulação de princípios e de orientações, parte que inclui a discussão acerca dos professores.

Nas orientações relativas aos professores, o Relatório afirma que a "Comissão pensa que todos os governos devem pôr especial empenho em reafirmar a importância dos professores da educação básica e criar condições para que melhorem as suas qualificações" (Delors, 2003, p. 159). Para tanto, indica a necessidade imperativa de adoção de nove medidas: as sete primeiras relacionadas a recrutamento, formação dos professores, modos de gestão e de participação da comunidade, a última ligada ao uso de tecnologias e formulação de programas de ensino, sendo que as condições de trabalho aparecem unicamente no penúltimo item.

Embora o documento afirme que "todos os governos devem pôr especial empenho", ao longo do mesmo prevalecem comentários genéricos que não explicitam os agentes responsáveis por criar as condições de efetivação e as mudanças necessárias. Desse modo, a menção à necessidade de "manter a motivação dos professores em situação difíceis e, para conservar no ensino os bons professores, oferecer-lhes condições de trabalho satisfatórias e remuneração comparável à das outras categorias" (idem, ibid., p.160-161), aspectos que nos parecem adequados e desejáveis, não é considerada pela grande maioria dos sistemas públicos de ensino.

O Relatório afirma que "os professores reivindicam, e com razão, condições de emprego e um estatuto que testemunhem o reconhecimento de seus esforços. É preciso dar-lhes instrumentos de que necessitam para poderem desempenhar melhor as suas várias funções" (idem, ibid., p. 165-166). Contudo, em que consiste e a quem caberia "dar-lhes instrumentos"? Como vemos, a questão das condições de trabalho, 
quando contemplada, é parcialmente reduzida à questão salarial ou ao reconhecimento do trabalho do professor no âmbito institucional e social, sem referência à criação de adequadas condições de trabalho - como carga horária de trabalho/de ensino, tamanho das turmas, razão professor/aluno, rotatividade/itinerância do professor (Sampaio \& Marin, 2004).

Além disso, a profissionalização e a especificidade da atividade do professor, aspectos já relevados pela Recomendação, são enfraquecidas pela expectativa de que os professores "cumpram a sua missão com dedicação e com um profundo sentimento de suas responsabilidades" (Delors, op. cit., p. 166). Daqui, podemos depreender uma concepção de trabalho do professor como atividade voluntária e individual, sem levar em conta os condicionantes concretos do seu trabalho, tais como grande número de alunos em sala de aula, precariedade da infraestrutura física das escolas e condições de vida miserável da clientela escolar (o relatório abarca países em condições socioeconômicas bem mais precárias que o Brasil).

Ao tratar de alguns aspectos da formação e da carreira docente, deixando de lado as condições materiais para efetivação do trabalho, o Relatório Delors é marcado por uma concepção que vai de encontro à noção do trabalho como "atividade instrumentada e direcionada" (Amigues, 2004, p. 41) e pode reforçar a "individualização dos processos educacionais, a responsabilização individual pelo aprimoramento profissional, produz[ir] o afastamento dos professores de sua categoria profissional como coletivo e, em consequência, de suas organizações" (Freitas, 2003, p. 1108).

\section{0 trabalho docente no discurso da legislação educacional}

Destacamos a seguir alguns trechos do Parecer n. 9/2009 e da Resolução n. 2/2009 (Brasil, 2009a, 2009b) elaborados pela Câmara da Educação Básica do Conselho Nacional de Educação - Ministério da Educação. Com o objetivo de reformular as Diretrizes para os Novos Planos de Carreira e de Remuneração para o Magistério e de fundamentar o projeto da Resolução (editada como n. 2/2009),

o Parecer da relatora M. I. A. Noronha sistematiza o resultado do processo de audiências públicas efetivado em 2008, com a participação da sociedade civil e de entidades de classe.

Dentre os vários tópicos discutidos, destacamos os dois últimos itens - "Pressupostos educacionais, legais e sociais da nova Resolução" e "Alguns aspectos centrais da nova Resolução" - que tratam de aspectos do trabalho do professor:

(...) a escola tem que (...) possuir as condições objetivas necessárias para o desenvolvimento do processo ensino-aprendizagem, entre elas o número adequado de alunos em sala de 
aula, tempo de duração das aulas que confira dinamismo ao processo educativo e permita a interação entre as diferentes disciplinas, e um plano de carreira do Magistério que tenha como premissa o incentivo para que o professor nela permaneça, buscando sempre melhor qualidade para a escola pública. (Brasil, 2009a, p. 14)

"Visando garantir qualidade ao trabalho do professor", o documento estabelece critérios conforme as modalidades de ensino:

a) em cada escola, no máximo, uma média de estudantes por sala nos seguintes parâmetros: de 6 a 8 alunos por professor para turmas de educandos de 0 até 2 anos de idade; até 15 alunos por professor para turmas de educandos de 3 anos de idade (Parecer CNE/ CEB n. 22/98, p. 15); até 20 crianças por professor para turmas de educandos de 4 até 5 anos de idade; nos anos iniciais do Ensino Fundamental, até 25 alunos por sala; nos anos finais do Ensino Fundamental, até 30 alunos por sala, e no Ensino Médio até 35 alunos por sala;

b) nas redes de Ensino Fundamental e Médio, proporção nunca inferior a 1 (um) professor para 22 (vinte e dois) estudantes e 1 (um) técnico administrativo para 66 (sessenta e seis) estudantes, e no conjunto da Educação Infantil, da Educação do Campo e das demais modalidades que exigem proporção inferior para a consecução de oferta qualitativa, proporção fixada pelo respectivo sistema de ensino;

c) atribuição a cada docente de um número de turmas tal que nunca ultrapasse a 300 (trezentos) estudantes por professor em regime de, no máximo, 40 (quarenta) horas semanais em regência de classe, adequando, aos profissionais de disciplinas com carga horária reduzida ou de áreas de conhecimento afins, atribuições de aulas sem prejuízo em suas remunerações ou na carga efetiva de trabalho. (Brasil, 2009a, p. 19-20)

\section{Embora a relação entre qualidade e condições objetivas indicada no Parecer} possa ser tomada como um indício de avanço no sentido do estabelecimento de condições mais adequadas para o processo educativo, o próprio documento reconhece suas responsabilidades e limites no contexto de precarização e intensificação do trabalho docente (Oliveira, 2004, 2005, 2007; Assunção \& Oliveira, 2009):

O CNE reconhece que estas recomendações, ao contrário da composição da jornada de trabalho, não podem se transformar em norma geral a ser incluída na Resolução. Contudo, é responsabilidade da Câmara de Educação Básica do CNE traçar os caminhos da política de qualificação do ensino e de revalorização profissional dos educadores (...). Esperamos que essas Diretrizes contribuam para a superação dessa esdrúxula norma constitucional, que permite até 80 horas de trabalho semanal do magistério e é considerada por tantos como direito, quando, na verdade, é opressão. (Brasil, 2009a, p. 20)

Desse modo, ao abordar estes aspectos de forma mais inespecífica, a Resolução não mantém a mesma ênfase:

Artigo $4^{\mathrm{o}}$ - As esferas da administração pública que oferecem alguma etapa da Educação Básica (...) devem instituir planos de carreira para todos os seus profissionais do magistério (...) dentro dos seguintes princípios: (...) 
IV - reconhecimento da importância da carreira dos profissionais do magistério público e desenvolvimento de ações que visem à equiparação salarial com outras carreiras profissionais de formação semelhante; (...)

VII - jornada de trabalho preferencialmente em tempo integral de, no máximo, 40 (quarenta) horas semanais $[\ldots]$

VIII - incentivo à dedicação exclusiva em uma única unidade escolar; (...)

Artigo $5^{0}$ - Na adequação de seus planos de carreira (...) a União, os Estados, o Distrito Federal e os Municípios devem observar as seguintes diretrizes: (...)

VIII - promover, na organização da rede escolar, adequada relação numérica professoreducando nas etapas da educação infantil e nos anos iniciais do ensino fundamental, bem como número adequado de alunos em sala de aula nos demais anos do ensino fundamental e no ensino médio (...), a fim de melhor prover os investimentos públicos, elevar a qualidade da educação e atender às condições de trabalho dos educadores. (Brasil, 2009b, p. 41-42)

Em termos da concepção de trabalho docente, os princípios e as diretrizes da Resolução são marcados pelo entendimento de que o trabalho do professor se dá na confluência de aspectos relacionados ao trabalho docente, destacando princípios relativos às condições de acesso, remuneração, progressão na carreira, valorização do tempo de serviço prestado, jornada de trabalho, dedicação exclusiva (artigo $4^{\circ}$ ), e formulando diretrizes relacionadas aos aspectos organizacionais e condições de trabalho, abrangendo itens como número de alunos em sala de aula, aplicação dos recursos, plano de carreira, formação continuada, gestão democrática (artigo 5º).

Entretanto, as afirmações mais contundentes do Parecer não são traduzidas em artigos na Resolução, como, por exemplo, a proposta de determinado número de alunos por sala nas diferentes etapas e modalidades de ensino é substituída pela genérica indicação de "adequada relação numérica"; a jornada de trabalho como "preferencialmente em tempo integral" sem indicação do número de turmas por professores; o incentivo à dedicação a uma única escola é mencionada sem explicitar como isso poderá ser feito.

O que implica o princípio de "reconhecimento da importância da carreira do magistério" quando as diretrizes não são específicas? Nesse sentido, apesar da Resolução trazer questões fundamentais para a discussão acerca do trabalho do professor, o fato do documento omitir providências e critérios para sua concretização tem como consequência sua pequena repercussão em termos da melhoria das condições concretas de trabalho do professor.

Cabe ainda elencar algumas considerações acerca do processo de avaliação do professor abordado no artigo $5^{\circ}$ da Resolução: a concessão de "incentivos de progressão por qualificação do trabalho profissional" será feita a partir dos seguintes referenciais: "dedicação exclusiva ao cargo ou função no sistema de ensino"; 
"elevação da titulação e da habilitação profissional"; " avaliação de desempenho, do profissional do magistério e do sistema de ensino", como processo a ser realizado de forma participativa. Ao afirmar que a avaliação de desempenho "deve reconhecer a interdependência entre o trabalho do profissional do magistério e o funcionamento geral do sistema de ensino" e que objetiva o "aprimoramento do processo educativo", o documento explicita concepção de trabalho docente que articula desempenho do professor e funcionamento do sistema de ensino (Brasil, 2009b). A fim de compreender como estes princípios foram considerados, propomos um olhar mais atento para os documentos sobre avaliação docente.

\section{Possíveis implicações do silenciamento acerca das condições de trabalho}

Ainda, dentre os documentos produzidos no âmbito governamental, destacamos duas Portarias Normativas do Ministério da Educação, de 2010 e 2011, que tratam do processo de avaliação docente. Após o posicionamento contrário à proposta de implantação do Exame Nacional de Ingresso na Carreira Docente da Portaria Normativa n. 14/2010, por parte de entidades acadêmico-científicas da área da educação (Anfope, Anpae, Anped, Cedes e Forundir), foi publicada a Portaria Normativa n. 3/201, que revogou e alterou a anterior em vários pontos. Dentre as mudanças, destacamos a proposição da Prova Nacional de Concurso para Ingresso na Carreira Docente e a instituição de um Comitê de Governança de caráter consultivo, com membros de entidades acadêmico-científicas e classistas, para assessorar o Instituto Nacional de Estudos e Pesquisas Educacionais Anísio Teixeira (Inep) em assuntos relacionados à prova (matriz de referência, procedimentos e formas de adesão e inscrição).

Considerando que as portarias não abordam diretamente o trabalho docente e que a definição de vários aspectos da prova ainda está em andamento, problematizamos algumas ênfases deste processo. Ou seja: quais são as possíveis implicações do silenciamento sobre as concretas condições de trabalho (consideradas no Parecer n. 9/2009 e Resolução n. 2/2009) nos documentos sobre avaliação do professor ingressante?

Em nosso ponto de vista, a ausência desta temática tem como efeito reafirmar o atrelamento da melhoria da qualidade da educação básica ao perfil profissional. A partir de leitura de alguns documentos produzidos pelo Inep ao longo dos últimos dois anos, quando a discussão sobre Exame e, posteriormente, Prova se tornou mais presente, é possível sublinhar o reconhecimento do professor, de modo quase exclusivo, para a melhoria da qualidade da educação e a efetivação das políticas educacionais. O documento Referenciais para o Exame Nacional de Ingresso na Carreira Docente, de 2010, menciona o "levantamento sobre os fatores comuns ao perfil de 
um bom professor em diversos países" (Brasil, 2010a, p. 6) e a análise de outros documentos relacionados à educação brasileira. Segundo o Documento Aberto ao Comitê de Governança, de 2011, o perfil básico nacional foi estabelecido a partir da análise da legislação e das "experiências de países que fizeram discussões para o estabelecimento de um perfil básico nacional comum para os docentes ou que possuíam processos avaliativos estabelecidos em nível nacional" (idem, 2011a, p. 3), com base em documentos nacionais e internacionais, sem menção específica a nenhum deles.

Nesse sentido, nos parece importante retomar que, nos Referenciais de 2010, a argumentação em favor da definição do perfil profissional lança mão do estudo Teachers matter, elaborado pela Organização para Cooperação e Desenvolvimento Econômico (OCDE):

Segundo estudo da OCDE sobre políticas para o magistério, a prioridade geral dos gestores educacionais deveria ser definir de forma clara e concisa o que se espera em relação aos conhecimentos e habilidades dos professores, ou seja, definir padrões para um bom professor. (Brasil, 2010a, p. 1)

Os Referenciais destacam a relação qualificação/conhecimento do professor e qualidade de ensino sem considerar o conjunto de medidas sugeridas pelo estudo Teachers matter (OECD, 2005), que inclui: tornar a docência uma carreira atrativa, capacitar os professores, selecionar e contratar os professores, conservar os professores eficientes nas escolas, formular e aplicar políticas voltadas à profissão docente. Desse modo, o fato da qualificação e conhecimento do professor serem privilegiados nos Referenciais, em detrimento dos demais aspectos, é um alerta com relação às propostas em discussão: em que medida a proposta da Prova Nacional de Concurso para a o Ingresso na Carreira Docente, ao definir um perfil profissional, reitera concepção de trabalho docente como atividade individual e descontextualizada? Como parte de uma política educacional mais ampla, juntamente com a proposta da Prova, que medidas relacionadas à valorização da profissão docente podem ser tomadas para que o processo de melhoria da qualidade do sistema educacional não se reduza à avaliação do professor?

Assim, dentre os riscos que a implantação da Prova implica, destacamos a lógica e o modelo da avaliação. A lógica que, centrada na qualidade da educação e fortalecida principalmente a partir dos anos de 1990 como parte do processo de regulação do trabalho docente (Freitas, 2003, 2007), pode gerar provas que deixam de ser o meio para se tornarem o "fim para dar acesso a melhores padrões de qualidade" (Gentili, 1995, p. 153). Quanto ao modelo, a avaliação efetivada a partir de "procedimentos na forma de grades, constituindo-se em ferramentas relativamente padronizadas e estabilizadas" (Schwartz, 1998, p. 2), pode levar a um processo de afastamento e desconhecimento da situação de trabalho, no que diz respeito às 
prescrições, coletivos de trabalho, regras do ofício, ferramentas e instrumentos para desempenhá-lo.

A proposta de uma prova nacional pode levar a um modelo de avaliação no qual o domínio de saberes prevaleça em detrimento da valorização do magistério como "condição docente", reiterando concepção que desconhece a especificidade e os condicionantes do trabalho docente. Como já apontado na Resolução n. 2/2009, parte de uma política educacional, a avaliação do profissional da educação não pode se desvincular do trabalho e do funcionamento geral do sistema de ensino ou, em outras palavras, das condições materiais do trabalho.

A nosso ver, portanto, a proposta da Prova Nacional traz contradições que só serão superadas no enfrentamento da situação de modo mais ampliado: o processo de avaliação do "perfil profissional para os ingressantes na carreira docente das redes públicas de ensino" (Brasil, 2011a, p. 4) é apenas uma entre as múltiplas faces do processo de melhoria da qualidade do ensino, que inclui a atratividade e valorização da carreira docente, as condições de trabalho e de remuneração. De modo isolado, a Prova não pode garantir mudanças na qualidade do ensino.

\section{As condições de trabalho docente no discurso de uma entidade de classe profissional}

Destacamos ainda uma publicação da CNTE, confederação que congrega diversas entidades de profissionais da educação, o número 21 da revista Cadernos de Educação - Diretrizes para a Carreira e Remuneração -, entendendo que os artigos reunidos neste volume vão ao encontro das reivindicações da entidade e, desse modo, reiteram seu discurso.

Contemplando grande parte dos problemas e apontamentos do estudo Retrato da escola, Vanelli (2009) retoma quatro princípios fundamentados nas reivindicações da CNTE e vincula valorização do magistério e melhoria da qualidade do ensino público. Os princípios abarcam diretrizes relacionadas a salários, ingresso na carreira e políticas de incentivo à permanência na unidade escolar, qualidade do ambiente escolar, educação básica como direito de todos e dever do Estado, e gestão democrática da escola. O Princípio II afirma que a qualidade dos ambientes escolares, o modelo de gestão, a razão do número de alunos/professor, as condições de trabalho pedagógico e funcional, a valorização do magistério, os planos de carreira e remuneração têm impacto direto no desempenho dos trabalhadores e na qualidade do ensino.

Este princípio, ao reconhecer a articulação entre condições de trabalho e qualidade do ensino, traz concepção de trabalho docente como contingenciado por 
condições materiais de ordem institucional, social e econômica. Assim, como um discurso produzido no âmbito de uma entidade sindical que produz e faz circular determinados argumentos e que tem como destinatários não somente os trabalhadores da educação, a formulação dos princípios condensa expectativas e reivindicações bem definidas com relação às condições de trabalho. Aqui, a posição dos interlocutores é fator altamente significativo para as reivindicações postas, pois, apesar de alguns destes aspectos serem mencionados em outros documentos, aqui isto é tratado de maneira mais enfática.

\section{O trabalho do professor: condições concretas e prescrições oficiais}

Voltando agora ao professor, perguntamos: Como os discursos e as concepções veiculadas pelos documentos oficiais que tratam do professor afetam a atividade e as representações que ele tem de seu próprio trabalho?

Entendemos que a atividade de trabalho se constitui na reelaboração das prescrições, mediada pelos recursos materiais e simbólicos disponíveis. A análise do ensino como trabalho implica a articulação entre prescrições contidas nos documentos oficiais, constituição da profissionalização, condições de efetivação do trabalho pelo professor e condicionantes sócio-históricos mais amplos (Amigues, 2004; Machado, 2007).

Os documentos prescrevem e prefiguram sentidos. As concepções que os documentos oficiais trazem acerca do trabalho do professor integram as condições materiais e simbólicas nas quais a atividade de ensino é produzida e, assim, marcam a forma como o professor compreende seu próprio trabalho. Nesse sentido, fazem parte das prescrições que o trabalhador renormaliza nas situações de trabalho: constitutivas do trabalho realizado, as prescrições trazem embutidas algumas hipóteses acerca do real do trabalho, ou seja, concepções que atribuem responsáveis para aquilo que não foi possível realizar, para aquilo que foi impedido ou suspenso na situação de trabalho (Bronckart, 2006; Clot, 2006; Dejours, 2004; Lousada, 2004; Rosa, 2000; Schwartz, 2000).

Por meio da análise dos documentos que tematizam o trabalho docente, destacamos que as diferentes concepções presentes nestes documentos podem ser correlacionadas às posições ideológicas que os locutores ocupam no debate acerca desta atividade, entendendo que a divergência entre estas posições é indício das intensas disputas neste contexto.

Uma posição que vincula qualidade de educação à formação e qualificação do professor, sem indicar a melhoria das condições de trabalho, reitera o argumento de culpabilização individual do professor, considerado mal preparado pelos sistemas 
de avaliação, calcado no discurso de que a qualidade de ensino depende quase que exclusivamente do processo de formação do profissional. Neste processo, a criação de condições de trabalho mais adequadas, entendidas aqui de modo mais amplo, sai do foco das preocupações e dos problemas a serem enfrentados pelos sistemas públicos de ensino. A precariedade das condições de trabalho (que não se reduz à falta de estabilidade no emprego e flexibilização dos postos de trabalho, mas àquilo que compromete e impede a realização da atividade profissional) é desconsiderada e, até mesmo, escamoteada (Bourdieu, 1998; Oliveira, 2004; Sampaio \& Marin, 2004).

Como explicitamos, outra posição que perpassa alguns documentos vincula a qualidade do ensino aos vários fatores que constituem o trabalho e traz as condições de trabalho ao lado da formação e da valorização da profissão. Em acordo com esta posição, entendemos que o trabalho do professor se constitui na constante tensão entre formação e atuação profissional, processo no qual a formação do professor é condição fundamental, mas não exclusiva para a qualidade do ensino, como afirma Saviani (2009, p. 153):

(...) a questão da formação de professores não pode ser dissociada do problema das condições de trabalho que envolvem a carreira docente, em cujo âmbito devem ser equacionadas as questões do salário e da jornada de trabalho. Com efeito, as condições precárias de trabalho não apenas neutralizam a ação dos professores, mesmo que fossem bem formados. Tais condições dificultam também uma boa formação, pois operam como fator de desestímulo à procura pelos cursos de formação docente e à dedicação aos estudos.

Ao reconhecer o trabalho do professor em suas condições e especificidades, esta posição favorece a valorização do magistério como "condição docente". Sob este ponto de vista, uma perspectiva integral acerca da profissionalização dos docentes demanda maior conhecimento da especificidade da atividade de ensino como atividade "regulada explícita ou implicitamente, como uma atividade contínua de invenção de soluções, e, enfim, como uma atividade coletiva" (Amigues, 2004, p. 45). Lembramos que a noção de "condição docente" forjada nas Recomendações da Unesco-OIT, de 1966, ainda fora do contexto das reformas neoliberais, abarca vários aspectos que contingenciam a atividade de ensino e demarca promissora visão acerca do trabalho do professor. Ademais, diante do desconhecimento do que ocorre no trabalho de ensino, pensamos que estudos como Retrato da escola, que identificam contingências desta atividade, são fundamentais para romper com o processo de precarização do trabalho docente.

Em termos de como o professor e seu trabalho podem ser afetados pelos vários documentos, tendo em vista a quase hegemônica concepção de trabalho como apartado das condições sócio-históricas, é possível dizer que os efeitos destes discursos estão presentes nos processos vivenciados pelos professores, na forma como 
interpretam e lidam com as dificuldades e impossibilidades, na falta de valorização e reconhecimento das atividades profissionais relacionadas ao magistério e, até mesmo, na autorresponsabilização ou na culpabilização da criança e sua família pelo fracasso escolar e baixa qualidade do ensino.

Como destaca Clot (2006, p. 201), "o trabalho é ação e possui uma função psicológica precisamente porque põe o sujeito à prova de suas obrigações práticas e vitais com relação aos outros e com relação ao mundo. A ação não é uma iniciativa puramente individual oferecida aos outros, nem uma criação pessoal". Dessa forma, os diversos discursos produzidos acerca do trabalho do professor são constitutivos da própria atividade de trabalho e fazem parte do processo de ajustamento e de "apropriação psicológica" do trabalho pelo trabalhador. As condições concretas e as prescrições sobre o trabalho estão entrelaçadas na dinâmica de constituição do (trabalho do) professor, sempre em relação com as condições históricas e culturais mais amplas (Vygotsky, 1995).

Enfim, pensamos que a discussão desta temática não se encerra nos documentos que propusemos retomar, uma vez que não está circunscrita a eles, nem está, tampouco, concluída. Como podemos apreender a partir do debate no âmbito da educação, sempre objeto de tensão e de disputas acirradas, a questão do trabalho do professor permanece em pauta na formulação de documentos da política educacional. Acreditamos que a explicitação das concepções do trabalho do professor em relação com as condições de trabalho seja uma possibilidade de ampliar esta discussão.

\section{Notas}

1. Os relatórios sistematizam dados de diversas fontes: (1) Censo demográfico do IBGE, (2) Pesquisa Nacional por Amostras de Domicílio (PNAD), (3) Sistema de Avaliação do Ensino Básico (Saeb) do Inep, (4) Censo escolar do MEC (1995, 1997 e 1999), (5) dados da Unicef e (6) consulta nacional realizada pela CNTE, sobre violência, relações no trabalho, sofrimento psíquico do trabalhador em educação.

2. Unesco (Organização das Nações Unidas para a Educação, a Ciência e a Cultura), OIT (Organização Internacional do Trabalho), CNE (Conselho Nacional de Educação), CEB (Câmara de Educação Básica), MEC (Ministério da Educação), Inep (Instituto Nacional de Estudos e Pesquisas Educacionais Anísio Teixeira), CNTE (Confederação Nacional dos Trabalhadores em Educação).

\section{Referências}

ABBAGNANO, N. Dicionário de filosofia. 5. ed. São Paulo: Martins Fontes, 2007.

AMIGUES, R. Trabalho do professor e trabalho de ensino. In: MACHADO, A.R. (Org.). O ensino como trabalho: uma abordagem discursiva. Londrina: Eduel, 2004. p. 35-53. 
ASSUNÇÃO, A.A.; OLIVEIRA, D.A. Intensificação do trabalho e saúde dos professores. Educação \& Sociedade, Campinas, v. 30, n. 107, p. 349-372, 2009.

BARROS, B.C. "O trabalho docente em meio às frustrações: análise de situações vivenciadas por estagiários e professores"; orientação Ana Lúcia Horta Nogueira. Ribeirão Preto: FFCLRP-USP, 2009 (Fapesp: Bolsa de Iniciação Científica. Relatório final).

BOURDIEU, P. Contrafogos: táticas para enfrentar a invasão neoliberal. Rio de Janeiro: Zahar, 1998.

BRASIL. Ministério da Educação. Parecer CNE/CEB n. 9/2009, de 2 de abril de 2009. Revisão da Resolução CNE/CEB n. 3/97, que fixa Diretrizes para os Novos Planos de Carreira e de Remuneração para o Magistério dos Estados, do Distrito Federal e dos Municípios. 2009a. Disponível em: <http://portal.mec.gov.br/dmdocuments/ pceb009_09.pdf>. Acesso em: 22 mar. 2011.

BRASIL. Ministério da Educação. Resolução CNE/CEB n. 02/2009, de 28 de maio de 2009. Fixa as Diretrizes Nacionais para os Planos de Carreira e Remuneração dos Profissionais do Magistério da Educação Básica Pública. Diário Oficial da União, Brasília, DF, 29 maio 2009b. Seção 1, p. 41-42. Disponível em: <http://www.in.gov. $\mathrm{br} /$ visualiza/index.jsp?data=29/05/2009\&jornal=1\&pagina $=41 \&$ totalArquivos=216 $>$. Acesso em: 22 mar. 2011.

BRASIL. Ministério da Educação. Instituto Nacional de Estudos e Pesquisas Educacionais (Inep). Referenciais para o exame nacional de ingresso na carreira docente: documento para consulta pública. Brasília, DF: MEC/Inep, 2010a. Disponível em: $<$ http://consultaexamedocente.inep.gov.br/publico/download/Referenciais_para_o_ Exame_Nacional_de_Ingresso_na_Carreira_Docente.pdf $>$. Acesso em: $1^{\circ o}$ dez. 2010.

BRASIL. Ministério da Educação. Portaria Normativa n. 14, de 21 de maio de 2010. Diário Oficial da União, Brasília, DF, 24 maio 2010b. Seção 1. , p. 11. Disponível em: $<$ http://www.in.gov.br/imprensa/visualiza/index.jsp?jornal=1\&pagina=11\&data= 24/05/2010>. Acesso em: 1ํo dez. 2010.

BRASIL. Ministério da Educação. Instituto Nacional de Estudos e Pesquisas Educacionais (Inep). Documento Aberto ao Comitê de Governança. Brasília, DF: MEC/Inep, 2011a. Disponível em: <http://download.inep.gov.br/educacao_basica/prova_docente/ legislacao_documentos/2011/documento_aberto_ao_comite_governanca.pdf $>$. Acesso em: 20 set. 2011.

BRASIL. Ministério da Educação. Portaria Normativa n. 3, de 2 de março de 2011. Diário Oficial da União, Brasília, DF, 3 mar. 2011b. Seção 1, p. 44. Disponível em: <http:// www.in.gov.br/imprensa/visualiza/index.jsp?jornal=1\&pagina=9\&data=03/03/2011 >. Acesso em: 16 maio 2011. 
BRONCKART, J.-P. Atividade de linguagem, discurso e desenvolvimento humano. Campinas: Mercado de Letras, 2006.

BRONCKART, J.-P.; MACHADO, A.R. Procedimentos de análise de textos sobre o trabalho educacional. In: MACHADO, A.R. (Org.). O ensino como trabalho: uma abordagem discursiva. Londrina: Eduel, 2004. p. 131-163.

CLOT, Y. A função psicológica do trabalho. Petrópolis: Vozes, 2006.

CONFEDERAÇÃO NACIONAL DOS TRABALHADORES EM EDUCAÇÃO (CNTE). Retrato da escola 1. Brasília, DF: CNTE, 1999. Disponível em: <http://www.cnte.org.br/ images/pdf/pesquisa_retrato_da_escola_1.pdf>. Acesso em: 1ํㅡㄹ. 2010.

CONFEDERAÇÃO NACIONAL DOS TRABALHADORES EM EDUCAÇÃO (CNTE). Retrato da escola 2. Brasília, DF: CNTE, 2001. Disponível em: <http://www.cnte.org.br/ images/pdf/pesquisa_retrato_da_escola_2.pdf>. Acesso em: 1ํo dez. 2010.

CONFEDERAÇÃO NACIONAL DOS TRABALHADORES EM EDUCAÇÃO (CNTE). Retrato da escola 3. Brasília, DF: CNTE, 2003. Disponível em: <http://www.cnte.org.br/ images/pdf/pesquisa_retrato_da_escola_3.pdf>. Acesso em: 1ํo dez. 2010.

CONFEDERAÇÃO NACIONAL DOS TRABALHADORES EM EDUCAÇÃO (CNTE). Diretrizes para a carreira e remuneração. Cadernos de Educação, Brasília, DF, v. 14, n. 21, out. 2009.

CUNHA, C. Magistério: diretrizes de valorização e impasses. Cadernos de Educação, Brasília, DF, v. 14, n. 21, p. 145-161, out. 2009. Disponível em: <http://www.cnte.org. br/images/pdf/caderno_de_educacao_2009.pdf>. Acesso em 22 mar. 2011.

DEJOURS, C. Subjetividade, trabalho e ação. Revista Produção, São Paulo, v. 14, n. 3, p. 27-34, 2004.

DELORS, J. et al. Educação: um tesouro a descobrir; relatório para a Unesco da Comissão Internacional sobre Educação para o século XXI. 8. ed. São Paulo: Cortez; Brasília, DF: MEC; Unesco, 2003.

FREITAS, H.C.L. Certificação docente e formação do educador: regulação e desprofissionalização. Educação \& Sociedade, v. 24, n. 85, p. 1095-1124, dez. 2003.

FREITAS, H.C.L. A (nova) política de formação de professores: a prioridade postergada. Educação E Sociedade, Campinas, v. 28, n. 100, p. 1203-1230, out. 2007.

GENTILI, P.A.A. O discurso da "qualidade" como nova retórica conservadora no campo educacional. In: GENTILI, P.A.A.; SILVA, T.T. (Org.). Neoliberalismo, qualidade total e educação: visões críticas. 2. ed. Petrópolis: Vozes, 1995. p. 111-177. 
LOUSADA, E. Os pequenos grandes impedimentos da ação do professor: entre tentativas e decepções. In: MACHADO, A.R. (Org.). O ensino como trabalho: uma abordagem discursiva. Londrina: Eduel, 2004. p. 271-296.

MACHADO, A.R. Por uma concepção ampliada do trabalho do professor. In: GUIMARÃES, A.M.M.; MACHADO, A.R.; COUTINHO, A. (Org.). O interacionismo sociodiscursivo: questões epistemológicas e metodológicas. Campinas: Mercado de Letras, 2007. p. 77-97.

MACHADO, A.R.; BRONCKART, J.-P. De que modo os textos oficiais prescrevem o trabalho do professor?: análise comparativa de documentos brasileiros e genebrinos. Delta, São Paulo, v. 21, n. 2, p. 183-214, 2005.

NOUROUDINE, A. A linguagem: dispositivo revelador da complexidade do trabalho. In: SOUZA-E-SILVA, M.C.P.; FÄ̈̈TA, D. (Org.). Linguagem e trabalho: construção de objetos de análise no Brasil e na França. São Paulo: Cortez, 2002. p. 17-30.

OLIVEIRA, D.A. A reestruturação do trabalho docente: precarização e flexibilização. Educação \& Sociedade, Campinas, v. 25, n. 89, p. 1127-1144, 2004.

OLIVEIRA, D.A. Regulação das políticas educacionais na América Latina e suas consequências para os trabalhadores docentes. Educação \& Sociedade, Campinas, v. 26, n. 92, p. 753-775, 2005.

OLIVEIRA, D.A. Política educacional e a reestruturação do trabalho docente: reflexões sobre o contexto latino-americano. Educação \& Sociedade, Campinas, v. 28, n. 99, p. 355-375, 2007.

ORGANISATIONFORECONOMICCO-OPERATIONANDDEVELOPMENT(OECD). Teachers matter: attracting, developing and retaining effective teachers (extended overview). 2005. Disponível em: <http://www.oecd.org/dataoecd/39/47/34990905. pdf $>$. Acesso em: 8 fev. 2011.

ROSA, M.I. Trabalho - nova modalidade de uso de si e educação: debates/ confrontos de valores. Pro-Posições, Campinas, v. 11, n. 2 (32), p. 51-68, 2000.

SAMPAIO, M.M.F.; MARIN, A.J. Precarização do trabalho docente e seus efeitos sobre as práticas curriculares. Educação \& Sociedade, Campinas, v. 25, n. 89, p. 1203-1225, 2004.

SAVIANI, D. Formação de professores: aspectos históricos e teóricos do problema no contexto brasileiro. Revista Brasileira de Educação, Rio de Janeiro, v. 14, n. 40, p. 143-155, 2009.

SCHWARTZ, Y. Pensar o trabalho e seu valor. Ideias, Campinas, v. 3, n. 2, p. 109-121, 1996. 
SCHWARTZ, Y. Os ingredientes da competência: um exercício necessário para uma questão insolúvel. Educação \& Sociedade, Campinas, v. 19, n. 65, p.101-140, 1998.

SCHWARTZ, Y. Trabalho e uso de si. Pro-Posições, Campinas, v. 11, n. 2 (32), p. 34-50, 2000.

UNESCO. Recomendação relativa à condição docente; aprovada pela Conferência Intergovernamental Especial sobre a Condição Docente. Paris: Unesco, 1966. Disponível em: <http://unesdoc.unesco.org/images/0015/001515/151538por.pdf>. Acesso em: 22 mar. 2010.

VANELLI, M. Do piso salarial aos planos de carreira: a que princípios estão submetidos estados e municípios? Cadernos de Educação, Brasília, DF, v. 14, n. 21, p. 106-116, 2009. Disponível em: <http://www.cnte.org.br/images/pdf/caderno_de_educacao_2009. pdf>. Acesso em: 1ํ dez. 2010.

VYGOTSKI, L.S. Obras escogidas. Madrid: Visor, 1995. v. 3.

Recebido em 5 de novembro de 2011.

Aprovado em 30 de agosto de 2012. 